\title{
Good reasons for losers: lottery justification and social risk
}

\author{
Kai Spiekermann (iD) \\ Department of Government, London School of Economics, Houghton Street, London WC2A 2AE, UK \\ Email: k.spiekermann@lse.ac.uk
}

(Received 10 August 2019; revised 18 December 2020; accepted 12 January 2021; first published online 12 April 2021)

\begin{abstract}
Many goods are distributed by processes that involve randomness. In lotteries, randomness is used to promote fairness. When taking social risks, randomness is a feature of the process. The losers of such decisions ought to be given a reason why they should accept the outcome. Surprisingly, good reasons demand more than merely equal ex ante chances. What is also required is a true statement of the form: 'the result could easily have gone the other way and you could have been the winner'. This rules in standard lotteries but rules out many lotteries based on merely epistemic probability.
\end{abstract}

Keywords: Lottery; social risk; randomness; determinism; contractualism

\section{Introduction}

Many goods are distributed by processes that are partly or fully random: lots are drawn, risks are distributed, gambles are taken. Once the dies are cast, there are winners and losers. The losers demand to know why they should accept the implications of being losers. In this paper, I want to focus on the losers, and especially on the reasons we can and cannot give them to justify their predicament. There are two main processes for distributing goods randomly on which I am going to focus: lotteries and social risk imposition.

First, lotteries. Oftentimes the use of randomness is a deliberate choice - we employ lotteries to allocate scarce indivisible goods. For instance, we might toss a coin to decide who among two equally deserving claimants gets the one available kidney. Many arguments have been offered for the use of lotteries, but one has been largely overlooked: Lotteries give good reasons to the losers for why they should accept being on the losing side. Namely, that a non-arbitrary procedure was used that easily could have made them win. And what makes this statement true, I will argue, is that the person who could have been the winner in a possible world is not only numerically identical but also psychologically similar to the loser. 
Second, social risk. Sometimes randomness is not deliberately chosen for fairness reasons but an unavoidable feature of distributive processes. This is so when the creation of overall expected benefits comes with expected risks. In such situations, a random process creates winners and losers. The losers can ask for reasons why they have been subject to losses for gains accrued by others. Again, we need good reasons for losers. One (but not the only) marker of such a good reason is that the losers could easily have been the winners.

Whether imposed lotteries or social risk, we end up with winners and losers determined by a (supposedly) random process. In the case of lotteries, a designer of allocative rules ought to care about finding a procedure that establishes a good reason why the loser cannot have the good. In the case of social risk, we should ask why the loser should accept a gamble that looked good ex ante but is a bad predicament ex post. If this is correct, then having a theory that explains which reasons are good reasons to give to losers would be useful. This paper contributes to such a theory.

Whether it is permissible to impose social risks is often analysed in terms of contractualist theories. Contractualists reject aggregative approaches and instead focus on minimizing the strongest individual complaint against a chosen policy. Within this camp, the dividing line is roughly between ex post contractualists (e.g. Reibetanz 1998; Scanlon 1998; Rüger 2018) and ex ante contractualists (e.g. James 2012; Scanlon 2013; Frick 2015). The normative analysis of lotteries proposed in this paper relates to this debate in two ways. First, ex ante contractualist arguments are particularly suitable for justifying the use of lotteries as an allocation mechanism because they appeal to the prospect a lottery offers and the actual or hypothetical consent subjects give, based on that prospect. Second, however, a purely ex ante approach is unsatisfactory: justifications given ex post facilitate the expression of respect to a loser who must live with the consequences.

The first part of this paper is about lotteries. Lotteries are an instructive starting point because the design of the random process is fully in the hands of the allocator and the situation of the claimants is symmetrical before the lottery takes place. A series of examples in section 1 demonstrates that some lottery designs, even if they involve the same probabilities, provide better reasons to the losers of the lottery than others. Section 2 reviews existing theories of lottery fairness. A new theory of lottery justification based on reason-giving is presented in section 3 . Once the theory is established for lotteries, the implications for social risk (section 4) will be investigated. Section 5 addresses objections to some theories of lottery justification arising from determinism, while section 6 concludes.

\section{Four lotteries}

Imagine you must distribute an indivisible resource between two candidates $\mathrm{Y}$ and Z. Both claimants need the resource urgently, and, as far as can be established, their claims to it are equally strong. You can either give both an equal chance of the good in one of the ways described shortly or give the entire resource directly to $\mathrm{Y}$. (Imagine you cannot give it directly to $\mathrm{Z}$ for whatever reason.) I also stipulate that you are known to be scrupulously impartial between $\mathrm{Y}$ and $\mathrm{Z}$. Your 
impartiality implies that you prefer to allocate the resource by lottery rather than giving the resource directly to $\mathrm{Y}$. Further assume that the candidates cannot give prior consent to a procedure - you will have to choose the allocation mechanism and may be asked to justify your choice later. Let us also suppose that this situation arises regularly, though with different claimants. Your task is to formulate an allocation mechanism that you use consistently.

It is useful to distinguish between epistemic probability and objective chance. The probability of an event is epistemic if it is relative to a given set of evidence about the event and the process leading to it. For example, if I toss a fair coin and hide the result with a cup before I can see it, my epistemic probability of 'Heads' prior to lifting the cup is 0.5. Objective chance, however, is a trickier concept to pin down. I will work with a definition that makes the concept of chance palatable to some determinists, namely those determinists that are compatibilists about chance. To that end, I will say that there is an objective chance of an event occurring if that assessment is based on the widest set of evidence that is or could be available. ${ }^{1}$

For example, the chance of 'Heads' prior to a well-conducted toss of a fair coin is 0.5 (and not 0 or 1 ) because the outcome is not predictable with the widest set of evidence that is or could be available. This is the probability that rational experts would assign to the event after measuring all relevant properties of the coin, the method of throwing, the landing surface, and so on. By contrast, the objective chance of 'Heads' with the tossed coin hidden underneath the cup is either 0 or 1 . While I don't have the best evidence (given it is hidden from me), it is easily available in principle. While compatibilists about chance will find this plausible, committed incompatibilists reject important premises of the argument to follow. They might want to jump straight to section 5 and check whether the arguments provided there will allow them to suspend their incompatibilist beliefs before they continue with this paper.

One might think that lotteries with the same epistemic probability are interchangeable as far as reason-giving is concerned. Indeed, some extravagant lotteries have been proposed for the allocation of goods: to determine the winner by the size of the pancreas (the larger one wins; a lottery described but not endorsed by Kornhauser and Sager 1988), whose fingerprint is more similar to that of the last suspect arrested by the FBI (Wasserman 1996), or whether the number of stars in a distant stellar cluster is odd or even (Wasserman 1996). I will argue, however, that lotteries with the same epistemic probability, and even lotteries with the same objective chance at the time the stochastic process takes place, can differ in the quality of reasons they provide to losers. And, everything else equal, the lottery that provides better reasons is preferable. To show the differences, I present four examples, serving as intuition pumps. Later in this paper, I offer a hypothesis that systematizes all the intuitions these examples trigger. All examples involve equiprobable outcomes, but I argue that these lotteries are not all on a par.

\footnotetext{
${ }^{1}$ Here I take inspiration from Handfield's (2012) discussion of chance. I discuss the challenge of determinism in section 5 .
} 
The first example is the paradigm case of a fair lottery:

Coin Toss. Whenever you have to decide between two claimants, you toss a fair coin and allocate the good to $\mathrm{Y}$ if the coin lands heads (and to $\mathrm{Z}$ otherwise).

Here the random process leads directly to an outcome that determines the allocation of the good to either $\mathrm{Y}$ or $\mathrm{Z}$. The second example uses a more personal but still random property:

Symmetric Conception. You know that exactly one of the candidates $\mathrm{Y}$ and $\mathrm{Z}$ was conceived on an even calendar date (the $2 \mathrm{nd}, 4$ th, ...), and you believe, correctly, that it is equally likely $\mathrm{Y}$ or $\mathrm{Z}$. However, neither you nor the candidates know their day of conception prior to an easy test that you can conduct. When you need to allocate between $\mathrm{Y}$ and $\mathrm{Z}$ for the first time, ${ }^{2}$ you conduct the test and assign the good to the person conceived on the even date. ${ }^{3}$

This is a more extended random process. At some point in the past, the lottery determining conception, driven by stochastic parent choices, stochastic biological processes, and so on, determined the time of conception of $\mathrm{Y}$ and $\mathrm{Z}$. Now, many years later, the time of conception is used to allocate the good. One might think that the outcomes of this lottery are epistemically equiprobable and have the same objective chance. 'One might think' because the ex ante objective chance is arguably not well-defined, given that the subjects do not yet exist when the stochastic process takes place that determines their time of conception. This already indicates a first problem with conception lotteries: the lottery changes the candidates' identity, an issue I discuss in section 3. ${ }^{4}$

In some ways, Symmetric Conception is similar to Coin Toss. The initial random process has equal epistemic probabilities at the time the result is used. What differs is that the result is already determined long before it is used. I will argue that if both Coin Toss and Symmetric Conception are available as allocation mechanisms, Coin Toss ought to be chosen. This is because the loser of Symmetric Conception can demand a reason why he should accept the result and the allocator ought to choose a lottery that is justifiable to the loser. A good reason would truthfully suggest to the loser that he could easily have won. That is credibly true when using Coin Toss: the smallest perturbation of the coin would have reversed the outcome so that the loser was a whisker away from winning. The same cannot be said about Symmetric Conception. For the outcome to be reversed, the claimants need to have different dates of conception, and if they did, they would likely be genetically different. This is because a different time of conception

\footnotetext{
${ }^{2}$ For any subsequent time, you use a coin toss. This avoids the complaint that a repeated use of the procedure is unfair.

${ }^{3}$ For similar cases using physical characteristics, see Sher (1980). Let us assume (counterfactually) that the date and time of conception can be determined reliably.

${ }^{4}$ However, a possible response to this worry is that the chance that any one of two yet-to-be-born individuals will be conceived on an even date is still roughly 0.5 , even if the identity of these individuals is not yet determined.
} 
makes it exceedingly likely that a different sperm would have reached and fused with the ovum, and (because of meiotic recombination) different sperms very likely carry different genes.

This problem becomes even more severe for one claimant in a variant of the Conception case:

Asymmetric Conception. When you need to decide between claimants $Y$ and $\mathrm{Z}$ for the first time, you give the resource to $\mathrm{Y}$ if $\mathrm{Y}$ was conceived on an even date, otherwise to Z. Z's date of conception is irrelevant for the decision.

This example does not change any of the probabilities. The only new feature of Asymmetric Conception is that the allocation is now tied up closely with the identity of $\mathrm{Y}$, but not with the identity of $\mathrm{Z}$. I claim that if $\mathrm{Y}$ loses out in Asymmetric Conception, he has a stronger complaint than $\mathrm{Z}$ has if he loses out. Why? Because if Y loses, there wasn't any genuine possibility for $Y$ to have won. In fact, someone named $\mathrm{Y}$ and with a different genome could have won, but that is someone quite different from the actual Y.

The strength of a reason provided to a loser depends on whether the loser can plausibly be the winner in a close possible world (while applying the same lottery). That is not the case if the lottery used changes the identity of the claimants. But similar considerations apply when the reversal of the outcome requires the claimants to have lived a different life, even though they are genetically identical. The fourth example will demonstrate this point.

Until recently, some oversubscribed degree programmes at Dutch universities were allocated by lottery (Goudappel 1999). For instance, when applying for a degree in psychology it might be decided by lottery whether a student ends up in Amsterdam or Groningen. Let us assume that (unlike the actual system used at the time) the lottery assigns a unique natural lottery number to each applicant in this process, using a random device. Here is a proposal to use these numbers again years later:

University Lottery. When you need to allocate between claimants $\mathrm{Y}$ and $\mathrm{Z}$ for the first time, you assign the good to the person with the lower university lottery number.

Now consider claimants $Y$ and Z. Suppose both are 50 years old, having graduated from university 25 years ago. $Y$ went to Amsterdam and $Z$ to Groningen, and both were lucky to have been assigned to their preferred cities. Everyone has long forgotten the lottery numbers. $\mathrm{Y}$ and $\mathrm{Z}$ find each other competing for the same indivisible good, and the decision is made by looking up their old lottery number. $\mathrm{Y}$ wins. $\mathrm{Z}$ has a very high number, perhaps one of the highest numbers in the country, and therefore loses.

$\mathrm{Z}$, I maintain, has a complaint against using the university lottery number. The problem is not with the probabilities. $\mathrm{Y}, \mathrm{Z}$ and the allocator had equal epistemic probabilities prior to looking up the numbers and the stochastic process had objective equal chances at the time the numbers were drawn. The problem is, again, that the reason given to $\mathrm{Z}$ is not very convincing when using the 
university lottery number. 'You could easily have won' rings hollow for Z. Why? Note first, since $Z$ has a high lottery number, the result would very likely have been the same even if the other claimant had not been Y. But if the lottery number had been lower then, assume, $\mathrm{Z}$ would not have been assigned to Groningen. And if he had studied somewhere else, he would have made different friends, dated different partners, led a different life and ultimately be quite a different person from the one he is now. If that is true, then to tell $\mathrm{Z}$ that 'you could easily have won' this lottery is far-fetched. Someone who is numerically identical to $\mathrm{Z}$, but psychologically only weakly similar to Z, would have been the winner. $\mathrm{Z}$ may find this quite a poor reason, and he would be right to feel that way.

One set of objections needs to be addressed straightaway: There might be a further lottery involved in the role assignment of $\mathrm{Y}$ and $\mathrm{Z}$, an ersatz lottery neutralizing the problems with the Conception lotteries and University Lottery. For instance, if the names $\mathrm{Y}$ and $\mathrm{Z}$ are assigned in the order the claimants enter the lottery, and their order is the result of a random process, then this would effectively be a new lottery. To rule out this complication, assume that the role assignment of $\mathrm{Y}$ and $\mathrm{Z}$ is not itself a lottery. Also, to keep our attention trained on the lottery that matters, it is useful to make the roles $\mathrm{Y}$ and $\mathrm{Z}$ dependent on a criterion that is clearly normatively unsuitable for assigning the resource: for example, call the wealthier of the two claimants $\mathrm{Y}$ and the less wealthy $\mathrm{Z}$. Unless you as the allocator systematically want to benefit the wealthier of the two claimants, you should use a lottery to avoid benefiting wealthy $\mathrm{Y}$ even more.

Related problems might arise if the mechanism used for allocation changes quickly, introducing an implicit lottery about the choice of allocation process in each single case. It is best to avoid such complications by assuming, as I have above, that all decision rules are long-standing and consistently applied in the same way.

In the next section, I review the existing literature on lottery fairness before I develop my theory of lottery justification. If successful, the theory will systematize the intuitions about Coin Toss, Symmetric Conception, Asymmetric Conception and University Lottery.

\section{When and why are lotteries fair?}

When discussing the use of lotteries in allocation problems, three questions can be asked:

1. When are lotteries a fair (or the fairest) way to allocate goods?

2. Why are lotteries fair, when they are?

3. Which lotteries are justified?

The first question is the most familiar one from the literature on lotteries. The second question is about the functions lotteries serve, and how these functions make lotteries fair. The third question has been raised much less often. Perhaps this is because the answer is assumed to be clear: the justified lottery is the one 
that gives everyone the chance they deserve. I argue that this view is incomplete. But before I do this, I quickly need to address the first two questions to prepare the ground.

\subsection{When are lotteries fair?}

There is widespread agreement about the necessary conditions for the applicability of lotteries (Sher 1980; Broome 1984; Stone 2011):

Practical Indivisibility. The good to be distributed cannot be divided, or any attempted division leads to side effects so bad that it ought not to be divided.

Scarcity. There are more claims to the good than there are units of the good.

The scarcity condition mentions 'claims'. Broome $(1984,1990)$ explains that these are reasons for giving the good to the different claimants. The claims are always to be evaluated relative to the claims of others as a matter of fairness. Fairness creates new claims, namely the fairness claim towards satisfying claims in proportion to their strength' (Broome 1990: 95). Sher (1980), Wasserman (1996) and Stone (2008) maintain that lotteries require exactly equal claims to justify the use of a lottery. The idea is that the lottery acts like a tie breaker - and if the claims are not exactly equal, no tie needs to be broken. Broome, by contrast, suggests that lotteries can be used to satisfy the claims in proportion to their strength. This leads to:

Probabilities in Proportion to Fairness Claims. All subjects have a probability of winning in proportion to their fairness claim to the good(s) to be allocated.

For practical purposes, I will assume claims of equal strength in all examples discussed in this paper.

Finally, for lotteries to be the appropriate allocative method, respecting fairness claims must be more important than any other normative properties:

Primacy of Fairness. The reasons for respecting claims by means of a lottery outweigh any other normative reasons supporting other allocative principles.

One important function of Primacy of Fairness is to block the thought that maximizing goodness is always preferable to lotteries. If the argument for using a lottery is to succeed, respecting claims must be more important than maximizing goodness; otherwise one should simply choose the allocation causing the greatest good.

\subsection{Why are lotteries fair?}

There are at least three different functions of lotteries: they can help to avoid partiality and arbitrariness, they can express an attitude of impartiality, and they 
can - though this is more controversial - have a distributive function. I go through these three functions in turn.

First, lotteries have a distinct advantage as an allocation mechanism: because they are unpredictable and, if conducted properly, impossible to manipulate, they prevent partiality by the allocator or anyone attempting to bias the decision mechanism. This exclusion of inappropriate reasons influencing the allocation has a 'sanitizing' effect (Stone 2011: sec. 2.4). Lotteries are therefore the best decision method when any undue influence to benefit one claimant is undesirable. A lottery is also preferable over an arbitrary decision because the impartiality of the lottery is not just contingent but guaranteed, while arbitrary decisions could always be obliquely influenced by partial motives (cf. Sher 1980).

The sanitizing effect works best if the alternative to the lottery is an unconstrained arbitrary choice by the allocator. Giving the allocator a free pass to allocate for any reason she likes invites choices for the wrong reasons. However, if the allocator is more constrained in the options available, the sanitizing effect does not work so well. Suppose, as before, that a good can either be given directly to claimant $\mathrm{Y}$, or a lottery between claimants $\mathrm{Y}$ and $\mathrm{Z}$ can be used (giving the good directly to $\mathrm{Z}$ is not possible for whatever reason). The allocator ought to choose the lottery for fairness reasons. But the lottery does not fully sanitize: It is possible that the allocator chose the lottery not for fairness but because she is partial to $\mathrm{Z}^{5}$

A notable property of the sanitizing view is that it only demands the equality of epistemic probabilities. Lotteries can sanitize even if, unbeknownst to the subjects, the objective chances are not equal - for instance, if the subjects and the allocator discover later that the lottery was in fact not fair: the coin thrown was biased, the die was unbalanced, the lots not properly mixed, and so on. If no one was able to know of the bias ex ante, then no manipulation, no influence of untoward motives was possible. Even using a coin that is known to be biased can sanitize, as long as no one knows the direction of the bias before the head and tails are associated with outcomes and the coin is tossed. In the same vein, Wasserman (1996: 33) suggests to 'exploit impending discovery', such as using the count of stars in a newly discovered cluster as a quasi-random device. In those cases, the epistemic probabilities will be balanced while the objective chance is 1 for one event and 0 for all others.

Second, lotteries can also have an expressive function, signalling to the possible recipients that they are treated in an impartial and respectful manner (Wasserman 1996). The use of the lottery signals to the claimants that the allocator takes their claims seriously, in a manner that respects the claims in proportion to their weight. Since my own view has an important expressive component, I will say more about this below.

The distributive function of lotteries, third, is controversial. It suggests that lotteries give something to claimants that they care about. When faced with equal claims, an indivisible good and scarcity, fairness requires that we 'go some way toward treating the candidates equally: we can give them all an equal chance' (Broome 1984: 45). This interpretation of the distributive function also

${ }^{5}$ I am grateful to Alex Voorhoeve for bringing this problem to my attention. 
suggests that epistemic equiprobability is not enough. Why? Because giving someone an equal chance requires more than just believing that one gives someone an equal chance. Broome therefore rejects the idea that the fairness of a lottery depends only on epistemic probabilities. While he does not explicitly discuss the possibility of epistemic probability and objective chance coming apart, he does say that a candidate has a complaint if her winning was 'never on the cards' (Broome 1990: 98). This complaint applies, for example, when using the size of the pancreas to determine the allocation decision.

Broome's argument for the distributive view is based on the obligation to fairly respect claims. If all candidates have roughly equal claims to a good but we cannot give that good to everyone, then fairness demands that we give 'surrogate satisfaction' - the chance to obtain the good (Broome 1990: 98). This is, of course, not as good as receiving the good (after all, one cannot 'eat chances'; Wasserman 1996), but it is the best one can do to satisfy the competing claims. ${ }^{6}$

\section{You could easily have won}

In this section, I set out a theory to explain the intuitive reactions to Coin Toss, Symmetric and Asymmetric Conception, and University Lottery. The core claim of the theory is this. The allocator has the task to choose a lottery mechanism that does not only have a fair probability distribution; it should also provide the best possible reason why the loser should accept the outcome. In particular, the allocator ought to choose the lottery such that the loser could not reasonably reject the following argument:

You should accept the result of the lottery because it had fair probabilities and because the result of this lottery could easily have gone the other way such that you could have won.

The choice of lottery must be justifiable to the loser in principle. A reason ought to be given if the loser demands one, especially when prior consent was not given. To make the argument as plausible as possible, the allocator ought to choose or construe the lottery such that (for both possible losers) the actual loser could easily have been the winner, where 'easily' refers to the possibility of a reversed outcome, not to probabilities. And the allocator should reject lotteries that make that reason given to the loser less plausible.

It is useful to define some terms to state the theory clearly. Let the actual world be the world after the allocation decision has been taken and the winner is fixed. A converse world to an actual world is a possible world in which winner and loser are swapped while the same lottery is correctly employed.

What makes it true that the loser could easily have won the lottery? It is, first, that there is a nearby converse world. And second, looking from the perspective of the loser, the converse world must be nearby in a specific sense: the current loser must

\footnotetext{
${ }^{6} \mathrm{~A}$ similar point is made by Kornhauser and Sager (1998). They suggest that a lottery's justness could be grounded on the fact that the lottery allows an 'equal division of a good that is otherwise indivisible' (p. 496) and that equiprobability creates this sort of equality in expectations.
} 
be able to see themselves in the unactualized winner. To do so, loser and unactualized winner must be psychologically similar. Without that psychological similarity, it would not be correct to say to the loser: 'you could easily have won', where 'you' means the person as they currently are, with the properties they currently have.

Importantly, it is not enough to be psychologically close to someone who wins in an arbitrary way, such as a possible world in which the names of winner and loser get confused in the process. Instead, what is required is that the loser is psychologically similar to the winner in a nearby possible world in which the lottery under evaluation is conducted in regular fashion but with the outcome reversed. This is because the reason given must support the lottery and the outcomes it causes. After all, one can hardly defend an institution by referring to fortuitous ways in which it might be circumvented or made redundant by other intervening processes.

Different lotteries provide plausible reasons to the loser to different degrees. Coin Toss does this well, as even the smallest perturbation of the coin, which was tossed a few seconds ago, could have made the loser win. By contrast, to reverse the result of University Lottery, much larger changes are required. In a converse world, the loser must have studied in a different city and must consequently have lived a different life. The psychological difference between actual loser and winner in near converse worlds is large.

This leads to first three desiderata for lotteries:

Identity Preservation. For both possible losers, a reversal of fortunes using the same lottery, such that actual loser and counterpart winner are numerically identical, must have been nomologically possible and reasonably likely.

Easy Reversal. There are nearby converse worlds.

Psychological Similarity. The lottery is such that the winner in nearby converse worlds is psychologically similar to the loser in the actual world.

Identity Preservation is a necessary condition for the reason given to the loser being a good reason. If the loser could not have won the lottery while preserving identity, then any claim that she could have been the winner is not only cold comfort, it is simply wrong. We have already encountered such cases in the Conception Lotteries. Regarding conception, I assume that genetic identity is necessary for being the same person. I also assume that zygotes created on different days have different genomes with near certainty, as it is exceedingly unlikely that the same sperm will be involved, and different sperms from the same person carry different genes. ${ }^{8}$

\footnotetext{
${ }^{7}$ I assume the possibility of trans-world identity, not Lewis's counterpart theory. For the purposes of this paper, especially in relation to the Conception Lotteries, it suffices to assume that a necessary (though not sufficient) condition for numerical identity is genetic identity. See Mackie and Jago (2017).

${ }^{8}$ Here I follow the extensive literature on the non-identity problem and its biological foundations. See Parfit (1984: ch. 16). For the differences in sperm genomes, see Wang et al. (2012).
} 
Easy Reversal ensures that a different outcome was close, not a remote possibility. ${ }^{9}$ Most, perhaps all reasonable lotteries meet this criterion: the coin could easily have landed differently, winner and loser could easily have drawn a different university lot, or (ignoring identity concerns for a moment) someone could easily be imagined to have been conceived on a different day. One may query here whether Coin Toss and the other lotteries all score equally high in terms of Easy Reversal. But I assume that all lotteries discussed so far produce converse worlds that are close enough to pass the Easy Reversal test. What sets lotteries apart is not so much whether there are any nearby converse worlds at all, but whether there are nearby converse worlds in which the loser can see herself. The main purpose of separately stating Easy Reversal is to distinguish it from a different desideratum that picks up on the issue of the loser seeing herself as someone who could have won: Psychological Similarity.

Psychological Similarity says that an allocator ought to choose a lottery that leads to psychological similarity between loser and would-be winner in nearby converse worlds. Note that there are two measures of distance involved here that must not be confused: a general measure of distance between possible worlds, appealed to in Easy Reversal, and a distance of psychological proximity, which tracks the quality of reason that can be given to the loser. The focus here is on the latter, as the argument is about the reasons that can be given to the loser. Whether these reasons pertain to the loser depends on whether one can truthfully say to the loser that they could easily have won. ${ }^{10}$ Psychological Similarity comes in degrees: the higher it is, the more plausible this reason becomes.

Why is the claim that 'you could easily have won' important? Given the unfortunate allocation choice that must be made, a lottery is supposed to reconcile the loser with the outcome as much as possible. Rawls maintained, famously, that reconciling us with the world is a central goal of political philosophy (Rawls 2001: 3). In the same spirit, reconciliation is also a goal of the institutional designer choosing a lottery as an allocation mechanism. A lottery that is better at reconciling the losers with the outcome is pro tanto preferable.

But why is reconciliation provided by Psychological Similarity? First, maximizing psychological similarity is a way for the allocator to pay respect to the subjects. Second, it is also a way for the allocator to prevent retroactive disillusion, a feeling of disappointment pertaining to earlier mistaken beliefs, and especially illusory hopes and expectations. Both points require elaboration.

I start with the claim that a lottery that provides Psychological Similarity is an expression of respect from allocator to subjects. To respect a subject, the allocator needs to recognize that subject as the person that they actually are. That this form of recognition is important becomes clear once we consider other situations in which this recognition is lacking. Imagine, for instance, Republican Robert saying to his

\footnotetext{
${ }^{9}$ For the measurement of such degrees of possibility, see Kment (2014: sec. 2.3), who draws on Lewis (1973: sec. 2.5).

${ }^{10} \mathrm{An}$ unusual but conceptually possible type of lottery would be one in which all converse worlds are distant (Easy Reversal violated) but Psychological Similarity is nevertheless great. It is hard to construe a lottery that keeps psychological states almost fixed while changing the rest of the world substantially. This is because one's self-conception partly depends on how one relates to the world: a lottery that radically changes external context is unlikely to leave us psychologically unchanged.
} 
former partner, activist Democrat Dina: 'It's a pity that you're such a leftie. We would have worked out great as a couple without your politics.' This statement shows a lack of respect for Dina as a person because Dina would not be the person she is without her activism. Now, the allocator in a lottery is not a lover, but they too have some duties of respect. Choosing a lottery that will only allow reversals of the result if the loser is quite a different person is like saying: 'If you had been different you could easily have won this lottery.' And that fails to acknowledge that individuals can only be respected as the individuals they are, not as a placeholder or number.

The second point is about what I call 'retroactive disillusion' - the feeling of disappointment that one experiences when one figures out that one's hopes and plans were based on false assumptions. In the University Lottery, for example, the loser of the lottery would have hoped that she can win that lottery. However, once the result is announced, it is clear that that hope was always in vain, leading to retroactive disillusion. Individuals want to avoid this feeling of disillusion because it is prima facie better to hold true beliefs rather than false beliefs, especially when the false beliefs cause falsely optimistic assumptions about future benefits and options. If the allocator chooses Coin Toss instead of University Lottery, the illusory chance gets replaced with an objective chance. There will still be a loser and a winner, but the advantage of Coin Toss is that the loser of that lottery will not experience retroactive disillusion, as it is true until just before the coin is tossed that the loser can win.

In summary, Psychological Similarity captures an important aspect of lottery justification. It suggests that a win for the loser was 'on the cards'. Looking back, it means that the hope to be the winner was not based on an illusion. Looking forward, it means that the loser can live with the knowledge that the allocator chose an allocation process that nearly made her win, an important sign that her legitimate claims were taken into account and that she is respected as the person she is. Psychological Similarity therefore serves an important expressive function.

Defenders of traditional lottery theories will respond that fair epistemic probability is sufficient to be impartial between the subjects and to express equal respect. Why, they might ask, is it required to truthfully tell the loser that 'you could easily have won' if loser and winner are treated with perfect impartiality? This objection, however, misses the mark on two counts. First, if the allocator chooses between several lotteries, he still needs to justify choosing one over the other. And since the main relevant difference between lotteries such as Coin Toss and University Lottery is the different causal position of the random process and the resulting difference in Psychological Similarity, the allocator has an obligation to justify why he chose a lottery that differs on precisely that dimension. ${ }^{11}$ Second, asserting that a lottery is impartial responds to the charge of unfairness, but fairness is not the only value that is at stake here. A lottery can be perfectly fair in the impartial sense while providing poor reasons for why it should be accepted as an allocation procedure.

\footnotetext{
${ }^{11}$ The procedural importance of the process could also be the basis on which one could respond to the critique of the 'objective egalitarian mixed view' as presented by Hyams (2017). However, engaging with Hyams's intricate argument is beyond the remit of this paper.
} 
One might object that it is easy for the loser of University Lottery or Symmetric Conception to imagine a possible world in which they would have won with psychological similarity retained. Suppose the rule linking stochastic event and allocation is changed: even and odd conception days or high and low university lottery numbers are swapped in our examples. Of course, the loser might have been the winner if the allocator had arbitrarily swapped the allocation rule or an arbitrary mistake had happened. But to say to the loser that they could have been the winner as a result of arbitrary changes or mistakes is not a good reason for using that lottery. Pointing out that a different lottery or a mistake would have produced a reversal is not enough. Consequently, such arbitrary reversals are ruled out by my definition of a converse world - a converse world is a world in which the result is reversed by correctly employing the same lottery.

The objector might still insist that the loser is psychologically similar to the winner in near converse worlds because it is easier to imagine a converse world in which loser and winner are swapped, but everything else stays the same, than a world in which winner and loser live completely different lives or the same two people did not even exist. This argument is similar to Fine's (1975) objection to Lewis's (1973) analysis of counterfactuals. ${ }^{12}$ A counterfactual like 'If Nixon had pressed the button then there would have been nuclear annihilation' requires, in Lewis's analysis, that, if there are possible worlds in which Nixon presses, then there must be a world in which Nixon presses and annihilation occurs that is closer to the actual world than any world in which Nixon presses but no annihilation occurs. Fine points out that worlds after nuclear catastrophe are very dissimilar to the actual world, challenging Lewis's analysis of counterfactuals. Lewis responds by providing a system of similarity weights for measuring world similarity to escape the force of the counterexample (Lewis 1979: 472). Roughly, Lewis gives priority to the avoidance of 'miracles' over maximizing regions of match. And a world in which Nixon presses, but no annihilation follows, requires such a miracle.

My defence of Psychological Similarity takes a leaf of Lewis's book, but also points to some structural differences. For more precision, it is useful to state the counterfactual claim at stake more precisely:

(Close) If $\mathrm{L}$ had won this lottery, then $\mathrm{L}$ would have been very similar to the person $\mathrm{L}$ is now.

The Lewisian analysis suggests that (Close) is true iff: if there are converse worlds, in the converse worlds closest to the actual world, counterpart- $\mathrm{L}$ is very similar to actual-L. The next challenge, of course, is how to measure possible world distance. Lewis proposes a weighing rule that works well for my purposes. Let us return to the lottery examples to see how. A reversal of outcome in Symmetric Conception or University Lottery, while the subject remains psychologically similar, would require a Lewisian 'small miracle' - a deviation from the bio-physical laws of conception, for example, or a strangely resilient character

${ }^{12} \mathrm{I}$ owe this point to an anonymous referee. 
(i)

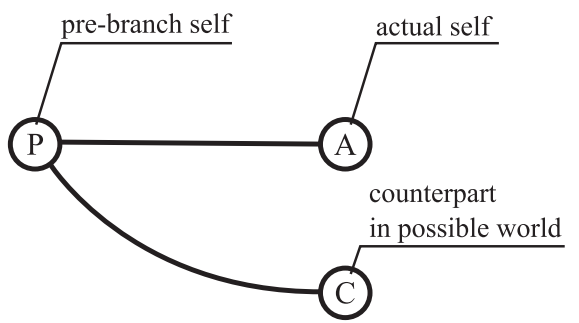

(ii)

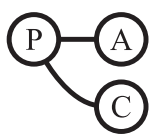

Figure 1. Two possible counterpart branching cases.

unchanged by exposure to different universities. By contrast, no such 'small miracle' is required to obtain psychological similarity in Coin Toss.

To support my case further, note that my argument only relies on the relative plausibility of different counterfactuals like (Close): I only defend the claim that (Close) is more plausibly true for lotteries like Coin Toss than for lotteries like University Lottery or Symmetric Conception. Such comparative claims are easier to defend because we do not need to weigh Lewis's different criteria of similarity against each other - (Close) is more plausibly true for Coin Toss because it does as well or better for all of Lewis's weighing criteria than other lotteries. This dominance makes the choice for the allocator obvious when Coin Toss is available.

Finally, why does the strength of the reason 'you could easily have won' increase with psychological similarity? To answer this question, a small excursion into the metaphysics of counterfactual identity is required.

One might ask: to what extent can it ever be true that I could have won the lottery (the lottery I actually lost), given that that alternative version of mine is on a counterfactual causal trajectory (see Velleman 2015)? Figure 1 helps to think through such claims. Let there be a pre-branch self $\mathrm{P}$; this is the self prior to the bifurcation of the causal paths. $\mathrm{P}$ develops into an actual self $\mathrm{A}$ at a later time. $\mathrm{A}$ also has a counterpart $\mathrm{C}$ in a possible, counterfactual world. ${ }^{13}$ In scenario (i), the branching caused by the lottery took place some time ago, as in University Lottery. In scenario (ii), by contrast, the branching is recent, as in Coin Toss. How do $\mathrm{A}$ and $\mathrm{C}$ relate, and does this relation differ in (i) and (ii)?

There is one important link between $\mathrm{A}$ and $\mathrm{C}$ that grounds $\mathrm{A}$ 's concern for C. A and C share many plans, ambitions, values, and other aspects of their selfconception because they are both successors of $\mathrm{P}$. In (ii), the overlap in attitudes between $\mathrm{A}$ and $\mathrm{C}$ will be substantial because they branched only recently. Psychological Similarity will be great. If, however, the branching happened a while ago, as in (i), then the plans, ambitions and values of $\mathrm{P}$ will have developed in different ways. Psychological Similarity will be smaller.

\footnotetext{
${ }^{13}$ Parfit, being specifically concerned with questions of personal identity and survival, looks at a close cousin of this setting (a 'branch-line case' in Parfit's terminology) in Parfit (1984: 199-201, 287-289).
} 
Therefore the reason given to the loser, 'you could easily have won', appeals to the loser of a lottery with recent branching, like Coin Toss. In these lotteries, there is a counterpart in a nearby converse world, sharing the same pre-branching self with the actual self, holding the same self-conception attitudes as the pre-branching self. Since this counterpart is close, the self can imagine itself in a counterfactual trajectory: all that is needed is to imagine the current self in a world with reversed outcome. Plans, goals or values stay the same. This counterpart is easy to identify with, and reasons that rely on connecting the counterfactual with the actual self are plausible in that respect. In lotteries like University Lottery, by contrast, the 'you could easily have won' points towards a counterpart with whom one shares (at most) only relatively distant memories and perhaps only traces of a former self-conception. Actual loser and winning counterpart have led different lives since branching and are therefore less close. One would need to try and see this counterpart as an alternative version of oneself, even though their plans, goals and perhaps even values would likely be different. Reasons that rely on connecting that counterfactual self with the actual self are in that respect less plausible.

It is time to put the final part of the theory in place. Apart from Identity Preservation, Easy Reversal and Psychological Similarity, the reasoning suggests one more desideratum for lotteries to provide good reasons to the loser:

Symmetry. The lottery should not, by design, cause differences in Psychological Similarity for both possible losers and their respective counterparts.

Symmetry is a fairness criterion. Both claimants have an equal claim to the good. Therefore, they also have a claim that the lottery is justified with reasons (in case they lose) just as strong as the reason that would have been provided to the loser in the converse world. Using a lottery design that treats the two claimants unequally in terms of the strength of the reason would be unfair. One can interpret Symmetry as an impartiality requirement in terms of the strength of justification that can be given to both possible losers.

Identity Preservation, Psychological Similarity and Symmetry partially order the different examples discussed above. Coin Toss satisfies all three desiderata best and is therefore the lottery that provides the best reason in the most equal way. Symmetric Conception and University Lottery satisfy Symmetry, but Symmetric Conception does not meet Identity Preservation (short of freak cases) and both lotteries certainly rule out close Psychological Similarity. Due to non-identity effects, it is very unlikely that the converse world contains both claimants of the same identity in the Symmetric Conception Lottery. It is therefore not convincing to say to the loser that 'you could easily have won' because 'you' would not have existed in most plausible converse worlds. In University Lottery, by contrast, the two claimants would remain at least genetically identical in nearby converse worlds, but important personal features would have to differ.

In Asymmetric Conception, the Symmetry desideratum is not satisfied. This example brings out that Identity Preservation and Psychological Similarity can be person-relative. In Asymmetric Conception, $\mathrm{Y}$ is in a special situation: his 
identity is so closely causally tied to the outcome that it is hard to see how the outcome could have been different for him. Whoever the person is that would be the winner in the converse world, they are someone with a different time of conception and therefore not identical with Y. For Z, by contrast, the only change needed is the change of one fact: the time of conception of a stranger. What is hardly plausible for $\mathrm{Y}$ is easy for $\mathrm{Z}$.

Asymmetric Conception is less fair than Coin Toss, Symmetric Conception and University Lottery because the Symmetry desideratum is violated. $\mathrm{Y}$ and $\mathrm{Z}$ will have very different views on how things could have gone differently and the reasons that could be provided to them as losers differ in strength. But Asymmetric Conception is good in one respect: it satisfies Identity Preservation and Psychological Similarity for claimant $Z$, whose time of conception is not tied to the outcome of the lottery.

The upshot is that Coin Toss is the best lottery, meeting all desiderata. Symmetric and Asymmetric Conception, as well as University Lottery, are inferior to Coin Toss in different ways. Asymmetric Conception is unfair because it provides reasons of different strength to the two possible losers. Symmetric Conception and University Lottery are not unfair, as they treat both claimants symmetrically. Still, they are less good lotteries than Coin Toss because they provide weaker reasons to each possible loser than other lotteries could have done.

My theory departs from a common position in the lottery literature: that the timing of the random process in the sequence of events making up the lottery does not matter. Elster, for example, asserts that '[f]airness does not require the random part in the sequence of events leading to the final decision to occur as late as possible, since one random event in the chain is enough to confer randomness on the outcome' (Elster 1989: 44). Kornhauser and Sager concur and add that Elster's assertion is underpinned by the 'principle of convolution' (Kornhauser and Sager 1988: 486). Wasserman, who thinks that fair epistemic probabilities suffice, is bound to agree that the timing of the random event is irrelevant. In his view, objective chance is not necessary, even though it is helpful to create the epistemic equiprobability Wasserman sees as indispensable. ${ }^{14}$ It is mathematically correct, of course, that one genuine random event suffices to make the overall outcome random. Moreover, when narrowly focusing on fairness (as in the Symmetry desideratum), many lotteries are admissible. But fairness through randomness is not all we want from a lottery - providing good reasons to losers is important as well. ${ }^{15}$

It is time to take stock of what has been achieved up to this point. The results so far provide a new theory of lottery justification based on reason-giving. Lotteries determine the expected values of the good ex ante, the allocation of the good, and the strength of the reasons that can be given ex post to both possible losers. Since the good cannot be shared, being able to provide a good reason to the

\footnotetext{
${ }^{14}$ Sher (1980) does not even insist on epistemic equiprobability as long as influence over the result for the wrong reasons are ruled out, but he would also agree that genuine randomness is helpful to avoid biases, regardless of timing.

${ }^{15} \mathrm{An}$ alternative theory of lottery justification could demand that (i) there are fair objective chances, and (ii) the stochastic lottery event takes place just prior to implementation. This would imply Psychological Similarity in all but highly unusual cases.
} 
loser is important - it is an expression of respect for the person who had a claim but receives nothing. The allocator can facilitate strong reasons to be given to losers by making the assertion 'you could easily have won this lottery' plausibly true for both possible losers. This leads to four desiderata: Identity Preservation, Easy Reversal, Psychological Similarity and Symmetry. These desiderata ensure that the same person could have won, that a reversal would have been easy, that loser and would-be winner are psychologically similar, and that, for both possible outcomes, Psychological Similarity is of the same extent, so that both possible losers would get reasons of the same strength.

\section{Social risk}

The recent debate on contractualist approaches to social risk imposition has structural similarities to the theory of lottery justice developed in this paper (see especially Frick 2015; but also Reibetanz 1998; Fried 2012; James 2012; Kumar 2015; Horton 2017). Social risk sometimes involves a random process that creates winners and losers. Whether the imposition of the risk is justified depends partly on whether good reasons can be offered to the losers of that process. In fact, providing good reasons to losers is at the very heart of the contractualist approach to social risk.

Typical situations of social risk arise when an allocator can take an action that affects many people such that each subject will accrue a benefit with high probability and a loss with low probability. ${ }^{16}$ In the lottery case, randomness is a chosen feature of the allocation mechanism to promote justice. In the case of social risk, by contrast, randomness is an unavoidable feature of a course of action offering benefits with risk. The question contractualists are asking is: are there reasons that can be given to losers that the losers cannot reasonably reject (Scanlon 1998)?

Frick discusses vaccinations, a classic case of social risk. A large benefit of prevented deaths or illnesses for many comes with a low probability of severe harm or death for those few unfortunate with vaccination complications. Consider, just as Frick does, a hypothetical vaccination programme that affects 1 million children. All children will be killed with certainty by a virus without the vaccination. Call this course of action.

No vaccination. All children die.

One vaccine is $100 \%$ reliable but also comes with a certain severe side effect. It serves as a

Baseline. All children survive, but they all have one leg permanently paralyzed.

All other vaccination programmes involve social risk. The difference in the programmes is about whether the identity of victims is fixed, and whether the identity is known:

\footnotetext{
${ }^{16}$ It is typically assumed that these individual events are statistically independent of each other.
} 
Victim Lottery. All children have a 999/1000 chance to live without complications and a $1 / 1000$ chance to die from freak complications, determined by a genuinely random process that takes place after the vaccine has been given.

Fixed Victims. 999,000 children will live without complications, but 1000 'doomed' children, whose identity is known, die with certainty, because of their genetic setup.

Frick, being an ex ante contractualist, wants to defend the choice of Victim Lottery over Baseline. Many ex post contractualists disagree. They appeal to the widely held intuition that Fixed Victims is seen as impermissible when Baseline is available because it is not permissible to sacrifice 1000 identified individuals for the greater good of the 999,000 others. They then assert that Victim Lottery is just as bad as Fixed Victim, on the grounds that, due to the law of large numbers, we are fairly certain that about 1000 victims will be determined by the lottery, leading to an outcome structurally similar to Fixed Victims. For ex post contractualists, all that matters is the existence of victims with a complaint at the end. Ex ante contractualists disagree - for them, it is only complaints based on information available prior to starting the allocation procedure that matter, which makes the choice of Victim Lottery over Baseline permissible. ${ }^{17}$

For this paper, however, I want to set this debate aside and instead focus on a case Frick mentions only indirectly and in passing:

Someone is Doomed. It is known that 1000 children are genetically 'doomed' to die when exposed to the vaccine, but it cannot be determined in advance who these children are because there is not enough time to perform the analysis.

Frick suggests that such cases are structurally similar to Victim Lottery because, at least for Frick, there is no difference between the purely epistemic probabilities of Someone is Doomed and the objective chanciness of Victim Lottery. Is Someone is Doomed just as good a choice as Victim Lottery? Frick suggests it is: 'Holding constant the fact of actually suffering a harm, it is typically no better for a person that she had some chance of escaping the harm rather than being certain to suffer it' (Frick 2015: 184). It is this claim I disagree with.

Frick defends his view by looking at the ex ante reasons that can be given to the losers of the vaccine programme. My objection to Frick's analysis is very similar to the objections against the Conception Lotteries above. For the 'doomed' children, winning was 'never on the cards', in Broome's felicitous phrase. Unlike Frick's thoroughly ex ante approach, I maintain that reasons after the allocation has proceeded are at least as important as the reasons given before. This is easiest to see by modifying the vaccine examples again. Assume that, instead of dying, unsuccessful treatment causes the children to develop a permanent disability and

\footnotetext{
${ }^{17}$ Assuming that having a paralyzed leg with certainty is much worse than the expected value of the gamble taken in Victim Lottery.
} 
chronic excruciating pain. This change brings out the importance of giving and receiving good reasons that are valid ex post, after the treatment has failed: since the children will live, the salience of giving plausible reasons shines through more clearly. ${ }^{18}$

After the fact, the victims will ask for reasons why the risk was taken that has caused them leading blighted lives. The best answer one can give for Victim Lottery is by now familiar: 'The result could easily have gone the other way and you would have benefited and be cured. Moreover, I would have given the same reason to the current beneficiaries if they had been one of the harmed.' Equally familiar is the observation that this statement is simply untrue when the victims were pre-determined, as is the case in Someone is Doomed. 'You' could not have been the winner - to be the winner, 'you' would have needed different genes, and that person would not have been you. Frick overlooks this important difference.

In fact, Frick argues that only epistemic probabilities can ever matter in these cases:

is there any greater self-interested reason to buy a ticket for a lottery where the prize will be allocated by a genuinely indeterministic mechanism [a "quantum randomizer"] than to buy a ticket for a lottery with the same epistemic odds where a ticket is either sure to win or sure to lose, in the objective sense [a scratch-card lottery with a preagreed winning number]? Again, it is hard to think of any such reason. If you had a ticket to the indeterministic lottery, and someone offered to trade it for an equivalent ticket to the deterministic lottery plus a small amount of cash, there would be no good reason to refuse this offer....

Nor could it be said that if the gamble goes badly, it is worse ... to become disadvantaged as the result of a causal process that was deterministic as opposed to indeterministic. The prudential value of receiving a chance of some good, whether epistemic or objective, is strictly parasitic upon the value of the good itself. (Frick 2015: 199)

This passage brings out my disagreement with Frick clearly. Frick asserts that it is rational to value deterministic and indeterministic lotteries in exactly the same way. But people often have preferences not just over outcomes but over the processes leading to outcomes, and such preferences are not necessarily irrational. It remains an empirically open question whether subjects do or do not value indeterminacy in lotteries when major losses are at stake. But most importantly, Someone is Doomed differs from a scratch-card lottery in one crucial respect: the loser in a scratch-card lottery could easily have been the winner if they (or the salesperson) had picked a different scratch-card, while the children in Someone is Doomed could never have been winners.

\footnotetext{
${ }^{18} \mathrm{Can}$ it be a coincidence that ex ante contractualists use examples in which the losers die? Dead losers do not ask for reasons!
} 
Whether objective chance and epistemic probability ought to be treated differently is a concern also taken up by Otsuka (2015). Otsuka construes this difference as a distributive matter: lotteries with objective chance distribute chance fairly (in Otsuka's cases: equally). But he maintains that the difference exists but 'should not count for that much' (p. 83). In a memorable thought experiment, Otsuka imagines that in order to save many people in the US's Midwest from certain death, there are two options. The first option is a large roulette wheel with objectively equal chances, which must be set into motion such that its ball will kill exactly one of 40 million Californians. The second option is to render one genetically pre-determined but unknown Californian quadriplegic to save the same people. According to Otsuka, spinning the wheel is less justifiable than rendering one determined but unknown person quadriplegic. But my analysis of lottery justification provides a reason for questioning this conclusion: the reason that 'you could easily have won' can truthfully be given (hypothetically or prior to death) to the loser of the wheel lottery, but not to the genetically pre-determined person now rendered paraplegic. Whether that reason tips the balance in this particular case is not crucial - what matters is that it might do so. My theory of lottery justification shows that here is an additional reason for avoiding imposing social risk on unknown but pre-determined victims: It is not only that objective chance has not been fairly distributed, it is also that lotteries with merely epistemic probability provide weaker reasons to the loser.

There is a wider lesson to be taken from this. The distinction between ex ante and ex post contractualists is too coarse. It misses the distinction between the time of reason-giving and the time at which the facts these reasons appeal to are true. My view is in favour of ex post reason giving, but these reasons appeal primarily to facts that are made true ex ante, especially modal facts about the lottery. Moreover, one could argue that the demand for reasons pertaining to ex post facts can already be demanded ex ante in anticipation. Note well that I do not endorse the standard ex post view that gives losers a veto merely based on the fact that they are the losers. This version of ex post contractualism, I concur with Frick, would lead to highly revisionary and quite unattractively status-quobiased prescriptions. Instead, my account of lottery justification shows, first, that giving good ex post reasons is important. And second, it reveals that the social risk literature misses important considerations by focusing almost exclusively on either ex ante prospects or ex post outcomes. It would be useful to pay more attention to other reasons a procedure can provide to the subjects ex post.

\section{The challenge from determinism}

Can one ever truthfully say to the loser that 'you could easily have won' if determinism is true? If the answer to that question is 'no', then my argument for the Psychological Similarity desideratum is only applicable if determinism is false. In this section, I show that determinism does not necessarily undermine my theory of lottery justification. 
A system is deterministic if the future trajectory through the state space of the system is fixed by the current state (and possibly also the past states) of the system. Determinism about the whole world means that the future of the world is fixed, given the history of the world.

Incompatibilists about chance hold that if determinism is true the world cannot be chancy and that consequently there are no objective probabilities apart from 0 or 1 in the world. This is the view that many participants in the debate about lotteries seem to assume by default. Examples of such incompatibilists are Frick (2015) and Sher (1980), a general overview of (in)compatibilism about chance is provided by Bradley (2017). With regard to lotteries, incompatibilists are committed to the view that the chances to win a lottery are epistemic only, while the objective probabilities of the outcomes are always either 0 or 1 . Lewis, for one, does not think that there is chance in a deterministic world:

To the question how chances can be reconciled with determinism, or to the question how disparate chances can be reconciled with one another, my answer is: it can't be done. (Lewis 1987: 118)

In the same spirit, Frick and Sher maintain that all lotteries with fair epistemic probabilities are equally justified, while objective chances for all claimants are impossible. Since there is no chance, the argument goes, it can never be true that 'you could have won'. Incompatibilism about chance is one reason why Frick sees no special problem with the purely epistemic lottery of the 'doomed children'. For him, all lotteries are epistemic only since there is no genuine chance in the world.

But is incompatibilism about chances plausible? Many are quick to make that assumption, in striking contrast to the literature on chance, which suggests that the issue is quite a bit more involved. Several philosophers have offered robust defences of compatibilism about chance in recent years (see Schaffer 2007; Glynn 2010; Bradley 2017). In this paper, I restrict myself to two quick comments. First, determinists who are incompatibilists will have a hard time to motivate the use of lotteries at all. They cannot say that a lottery gives claimants a fair, or indeed any kind of chance, because there is no chance. They might point to the sanitizing or expressive function of lotteries, but, as seen above, these theories lead to the counterintuitive result that biased coins are perfectly acceptable lottery devices. Second, historical counterfactuals like 'I could have won the lottery' (when we actually lost) are intuitively true if the lottery was conducted with a suitable stochastic device. Structurally similar historical counterfactuals are very much part of our everyday language (Placek and Müller 2007). We insist that 'The Yankees could easily have won, they were unlucky' or that 'I could have holed this short putt with a bit of luck' (cf. Austin 1979: 218, n. 1). The incompatibilist about chance must insist that all such statements are mistaken or need to be painstakingly re-interpreted without reference to chance.

The view I favour is compatibilism about chance, the view that a deterministic world can be chancy. Even if the physical world is fully deterministic on some level, this does not render the notion of objective probability obsolete (e.g. Hoefer 2007; Ismael 2009; Briggs 2010; Handfield 2012). One way to defend objective chance is to 
make it level-specific and to show that on the level of human agency determinism is false and objective chance exists, while on a lower level of description determinism may be true and objective chance does not exist. A concise review and a formally developed proposal can be found in List and Pivato (2015), with related arguments in Glynn (2010) and Emery (2015). If determinism is true, then a Laplacian demon, working on that lowest level, will be able to predict the outcome of every lottery with certainty. But for a human observer, even for a human observer with the best possible evidence they can gather, a well-constructed lottery is not predictable. Take a coin toss, for example. Assume that the coin is thrown high enough, with a strong initial spin. Also assume that the coin is allowed to hit the floor and bounce until it has settled on one side. ${ }^{19}$ To predict the outcome, the observer needs to have the starting position of the whole system with infinite precision, including the position of the coin, data about the initial forces from the throw, the atomic structure of the coin down to every single atom, any air movements, the position of all molecules, the surface on which the coin lands, and so on, and so forth. Any smallest deviation could lead to a different result. Good coin tosses are effectively unpredictable.

This shows that there is an important difference between a coin toss that is about to happen, and, for example, Frick's doomed children. According to our best scientific knowledge, no human being will ever be able to predict a well-executed coin toss, even with the best measurement devices. This is a nomological necessity, based on our best theories of the natural laws that govern chaotic, non-linear systems. For a compatibilist about chance, a coin toss is therefore chancy, and we can assign an objective probability strictly between 0 and 1 . The claim that 'you could have won' is therefore true from a human perspective, even if it isn't for an omniscient Laplacian demon. By contrast, in the case of Someone is Doomed, the outcome is, in principle, predictable.

The upshot of this is that compatibilists about chance can distinguish between the objective chance of a coin toss and the epistemic probability (at the time of allocation) of Conception Lotteries, University Lottery or Someone is Doomed. Compatibilists about chance can hold that determinism is true and still accept the reasoning in favour of the Psychological Similarity desideratum. For the compatibilist, the claim that 'I could easily have won the lottery' is true if the lottery is conducted with a suitable stochastic device and is not true if the lottery is merely based on epistemic uncertainty about an in-principle-predictable process.

Finally, not everybody believes that determinism is true. Our best physical theories suggest that determinism about the macro-physical world is likely true at least locally and at least most of the time, but that there is genuine randomness in the microphysical quantum world. If so, then the Psychological Similarity desideratum suggests that the best possible lotteries ought to employ quantum randomizers. ${ }^{20}$ And if we don't have a quantum randomizer at hand, we can at least use a maximally contingent, non-predictable stochastic process.

\footnotetext{
${ }^{19}$ This is surprisingly important. Without these additional random shocks there is an element of predictability left, as shown by Diaconis et al. (2007).

${ }^{20}$ Here is one: < https://qrng.anu.edu.au/>, last accessed 20 March 2021.
} 


\section{Conclusion}

This paper suggests that the normative literature on lotteries is incomplete and that normative theories of lottery justification need to be revised. Lotteries can have the same epistemic and even objective probabilities but - surprisingly - differ in the strength of the reasons they offer to the losers of the lottery. We should, pro tanto, prefer lotteries that provide stronger reasons to the losers, and - as a matter of fairness - reasons of equal strength to all possible losers. Being able to tell the loser that 'you could easily have won this lottery' is an important expression of respect. The allocator should aim for a lottery that makes this statement true, and plausibly so.

What applies to lotteries also applies, I have shown, to cases of social risk. Fairness requires that we offer all possible losers reasons of equal strength, and it is better if the reasons are stronger rather than weaker. That the losers would have been willing to take the risk ex ante is, by itself, a weak reason if they never had a chance to benefit. Proponents of ex ante contractualist approaches to social risk may worry about the ex post nature of the reasons my theory demands. But while reasons for losers apply ex post, they appeal to facts that are made true ex ante. This suggests that the ex antelex post distinction is too coarse to answer the question as to what kinds of reason we owe to the victims of social risk.

Acknowledgements. The idea for this paper was conceived jointly with Alex Voorhoeve. Many of the ideas presented here would not have emerged without our extensive discussions. I am very grateful for written feedback from Matthew Braham and Bastian Steuwer. I received helpful comments from Christian List, Keith Dowding, Bob Goodin, Alan Hajek, Geoff Sayre-McCord, Gerald Vong and many others, including audiences at Warwick University, the LSE, the ANU in Canberra, the Universities of Hamburg and Oldenburg, and a group of students from the German National Academic Foundation. Two anonymous referees and the editor, Itai Sher, provided generous, constructive advice, for which I am grateful. All remaining errors are mine.

\section{References}

Austin J.L. 1979. Philosophical Papers. Edited by J.O. Urmson and G.J. Warnock. Oxford: Oxford University Press.

Bradley S. 2017. Are objective chances compatible with determinism? Philosophy Compass 12, e12430.

Briggs R. 2010. The metaphysics of chance. Philosophy Compass 5, 938-952.

Broome J. 1984. Selecting people randomly. Ethics 95, 38-55.

Broome J. 1990. Fairness. Proceedings of the Aristotelian Society 91, 87-101.

Diaconis P., S. Holmes and R. Montgomery 2007. Dynamical bias in the coin toss. SIAM Review 49, 211-235.

Elster J. 1989. Solomonic Judgements: Studies in the Limitations of Rationality. Cambridge: Cambridge University Press.

Emery N. 2015. Chance, possibility, and explanation. British Journal for the Philosophy of Science 66, 95-120.

Fine K. 1975. Critical Notice: Counterfactuals by D. Lewis (Book Review). Mind 84, 451-458.

Frick J. 2015. Contractualism and social risk. Philosophy and Public Affairs 43, 175-223.

Fried B.H. 2012. Can contractualism save us from aggregation? Journal of Ethics 16, 39-66.

Glynn L. 2010. Deterministic chance. British Journal for the Philosophy of Science 61, 51-80.

Goudappel F. 1999. The Dutch system of lottery for studies. European Journal for Education Law and Policy 3, 23-27.

Handfield T. 2012. A Philosophical Guide to Chance. Cambridge: Cambridge University Press. 
Hoefer C. 2007. The third way on objective probability: a sceptics guide to objective chance. Mind 116, 549-596.

Horton J. 2017. Aggregation, complaints, and risk. Philosophy \& Public Affairs 45, 54-81.

Hyams K. 2017. On the contribution of ex ante equality to ex post fairness. In Oxford Studies in Political Philosophy, ed. D. Sobel, P. Vallentyne and S. Wall, 3, 11-35. Oxford: Oxford University Press.

Ismael J.T. 2009. Probability in deterministic physics. Journal of Philosophy 106, 89-108.

James A. 2012. Contractualism's (Not So) Slippery Slope. Legal Theory 18, 263-292.

Kment B. 2014. Modality and Explanatory Reasoning. Oxford: Oxford University Press.

Kornhauser L.A. and L.G. Sager 1988. Just lotteries. Social Science Information 27, 483-516.

Kumar R. 2015. Risking and wronging. Philosophy \& Public Affairs 43, 27-51.

Lewis D. 1973. Counterfactuals. Malden, MA: Blackwell Publishing.

Lewis D. 1979. Counterfactual dependence and Time's Arrow. Noûs 13, 455-476.

Lewis D. 1987. A subjectivists guide to objective chance. In Philosophical Papers Volume II, 83-132. New York, NY: Oxford University Press.

List C. and M. Pivato 2015. Emergent chance. Philosophical Review 124, 119-152.

Mackie P. and M. Jago 2017. Transworld identity. In The Stanford Encyclopedia of Philosophy (Winter 2017 ed.), ed. E.N. Zalta. https://plato.stanford.edu/archives/win2017/entries/identity-transworld/.

Otsuka M. 2015. Risking life and limb: how to discount harms by their improbability. In Identified and Statistical Lives: An Interdisciplinary Perspective, ed. G. Cohen, N. Daniels and N. Eyal, 77-93. Oxford: Oxford University Press.

Parfit D. 1984. Reasons and Persons. Oxford: Clarendon.

Placek T. and T. Müller 2007. Counterfactuals and historical possibility. Synthese 154, 173-197.

Rawls J. 2001. Justice as Fairness: A Restatement. Cambridge, MA: The Belknap Press of Harvard University Press.

Reibetanz S. 1998. Contractualism and aggregation. Ethics 108, 296-311.

Rüger K. 2018. On ex ante contractualism. Journal of Ethics and Social Philosophy 13, 240-258.

Scanlon T.M. 1998. What We Owe to Each Other. Cambridge, MA: Belknap Press of Harvard University Press.

Scanlon T.M. 2013. Reply to Zofia Stemplowska. Journal of Moral Philosophy 10, 508-514.

Schaffer J. 2007. Deterministic chance? British Journal for the Philosophy of Science 58, 113-140.

Sher G. 1980. What makes a lottery fair? Noûs 14, 203-216.

Stone P. 2008. On fair lotteries. Social Theory and Practice 34, 573-590.

Stone P. 2011. The Luck of the Draw: The Role of Lotteries in Decision Making. Oxford: Oxford University Press.

Velleman J.D. 2015. The identity problem. In Beyond Price: Essays on Birth and Death. Cambridge: Open Book Publishers.

Wang J., H.C. Fan, B. Behr and S.R. Quake 2012. Genome-wide single-cell analysis of recombination activity and de novo mutation rates in human sperm. Cell 150, 402-412.

Wasserman D. 1996. Let them eat chances: probability and distributive justice. Economics and Philosophy 12, 29-49.

Kai Spiekermann is Professor of Political Philosophy in the Department of Government at the London School of Economics. He works on democratic theory and the philosophy of the social sciences. Among his research interests are group decisions, social epistemology (and especially epistemic justifications of democracy), the ethics of environmental change, and the methodology of political theory and political science. His latest book (with Robert E. Goodin) is An Epistemic Theory of Democracy. URL: www. kaispiekermann.net

Cite this article: Spiekermann K (2022). Good reasons for losers: lottery justification and social risk. Economics \& Philosophy 38, 108-131. https://doi.org/10.1017/S0266267121000043 